\title{
ALADYM: an age and length-based single species simulator for exploring alternative management strategies
}

\author{
Giuseppe Lembo ${ }^{1, a}$, Alvaro Abella ${ }^{2}$, Fabio Fiorentino $^{3}$, Sergio Martino $^{1}$ and Maria-Teresa Spedicato ${ }^{1}$ \\ COISPA Tecnologia \& Ricerca, Via dei trulli 18-20, 70126 Bari, Italy \\ 2 ARPAT-AREA MARE, Via Marradi 114, Livorno, Italy \\ 3 IAMC-CNR, Via L. Vaccara 61, Mazara del Vallo (TP), Italy
}

Received 29 August 2008; Accepted 29 January 2009

\begin{abstract}
ALADYM (age-length based dynamic model) is an age-length based simulation model designed to predict the consequences of management scenarios on a single population, in terms of different metrics and indicators. Removals are simulated as total mortality modulated using a selectivity pattern and a fishing activity coefficient. ALADYM uses the classical equations of population dynamics to create a tool that uses fishery-independent information (e.g. from trawl surveys) as the primary source. The formulation of population dynamics at a small time scale (month) allows to model the effects of harvest controls that evolve through the year, which is particularly useful for fast growing species. The possibility of specifying a vector of natural mortality by age/length makes the model more suitable for situations where stocks are exploited at an early life stage, as in many Mediterranean fisheries, while introducing variations along the time of the harvesting pattern accounts for non-equilibrium situations. Stochastic effects can be added to some key life-history traits to incorporate uncertainty in input parameters and in their relationships. ALADYM can be used for a range of applications such as comparing management strategies, evaluating indicator changes or searching for reference points.
\end{abstract}

Key words: Fish population dynamics / Simulation model / Fishery-independent approach / Fishery management

\section{Introduction}

Fishery models are generally used to predict the long-term impact of fishing on stock dynamics and yield (Hilborn and Walters 1992; Gallucci et al. 1996; Quinn and Deriso 1999; Haddon 2001). However, the reliability of fishery-dependent data, on which the modern machinery of modelling for stock assessment is mainly based, is becoming of growing concern (e.g. Trenkel et al. 2007; Cotter et al. 2009).

Where time series of catch data are sparse, stock assessment and modelling of harvest control rules become difficult and impede the use of methods widely applied, for example, in the North Sea or in the Atlantic, e.g. virtual population analysis (VPA)/cohort analysis (Pope 1972; Darby and Flatman 1994) or surplus production models (e.g. Punt and Hilborn 1996; Prager 2005) or catch-survey analysis-CSA (Mesnil 2003).

ALADYM (age-length based dynamic model) is a simulation model that does not require fishery-dependent data, although it does have the capability to predict catches. The population at sea is mimicked by generating numbers at age (time and age scale in months) from a stock recruitment relationship (or from a recruitment vector) and using growth, maturity and sex-ratio parameters. Removals from the population are

\footnotetext{
a Corresponding author: lembo@coispa.it
}

also mimicked and, to do so, the total mortality rate estimated off-line from fishery-independent data (e.g. from trawl-survey and assessment techniques) is used as input. The model splits total mortality into fishing and natural mortality, the former modulated through a harvesting pattern and a fishing activity coefficient, the latter being a fixed value or a vector. In this way catches and natural losses are generated. To capture uncertainty inherent in the system, a Monte Carlo approach is implemented. Model setting is flexible and depends on the objectives. Several scenarios can be simulated, for instance predicting the impacts of the current exploitation pattern in the long-term, investigating how a management option might ultimately affect harvests and fish stocks, or hindcasting for exploring the behavioural dynamics of the model.

The design of ALADYM was motivated by the idea of developing a tool not requiring fishery-dependent data and able to cope with peculiarities inherent in the dynamics of fish populations characterised by a rather short life span (e.g. 58 years) and a fairly fast growth. Hence a monthly time scale was adopted although ALADYM can also deal with longerlived and slower growing fish. Another relevant issue driving the model design was the need to predict the effects of management strategies based on technical fishing regulations in situations when there are no reliable fishery statistics but good 
fishery-independent data (e.g. from trawl surveys) are readily available. This is the case for many Mediterranean fisheries, where the advisory (GFCM-FAO) and scientific communities, as well as coastal countries, consider that fishing effort control is the most suitable management approach for multispecies and sometimes multi-gear demersal fisheries, in particular if management interventions are complemented by closed seasons, no-take areas (to protect sensitive habitat and/or key life-stages) and limitations on gears (mesh size, gear geometry, etc.). In this context, management based upon total allowable catches (TACs) seems inappropriate as many demersal species are caught simultaneously. TACs or quota regimes are restricted to few cases of mono-specific fisheries, i.e. internationally shared resources as bluefin tuna and, at national levels, to a limited number of sedentary stocks (e.g. Chamelea gallina fisheries in the inshore western side of the Adriatic sea).

In some Mediterranean areas where a few years of commercial data are available, approaches such as length cohort analysis (LCA; see Lleonart and Salat 1997) have been applied. Alternatively, time trends in indicators (e.g. abundance indices and total mortality) estimated from trawl-survey data series have been used to evaluate the condition of some stocks (e.g. Anonymous 2002). Space-based data sets (abundance indices and total mortality) instead of catch and effort time series provided the fundamental information for implementing composite models (e.g. Abella et al. 1999), whereas life history parameters estimated from trawl-survey data have been used to build yield-per recruit curves (e.g. see Hoggarth et al. 2006 for a package of tools). These model-based exercises necessarily require specific assumptions regarding, for instance, an equilibrium state of the stock, and the dynamics of biological processes such as natural mortality.

In ALADYM, modelling uses monthly slicing of the population so as to allow cohorts to evolve simultaneously. Furthermore, the possibility of using a vector of natural mortality by age/length allows the model to go beyond the constant natural mortality paradigms (e.g. Caddy 2006) and thus to cope with situations in which stocks are exploited at an early stage as in many Mediterranean fisheries. Variations in time of the harvesting pattern can be included so that it is not necessary to assume that the stock is in an equilibrium state. Using a von Bertalanffy growth model, ALADYM implements an agelength approach that allows for biological and exploitation processes such as fast growth, growth-dependent mortality, continuous reproduction, or fishing on recruits. It also makes possible prediction of the consequences of different fishingpressure scenarios on population indicators that are easy to measure in the field, for example length for different groups, e.g. for the whole population, the immature stages, or for the spawners.

Indeed, the use of ALADYM is intended to assist with many diverse tasks in addition to simulation of population dynamics. These include:

- exploring and comparing alternative management scenarios in the medium and long-term;

- evaluating changes in the direction and sensitivity of indicators under different management regimes, e.g. the ratio of exploited to unexploited spawning stock biomass;

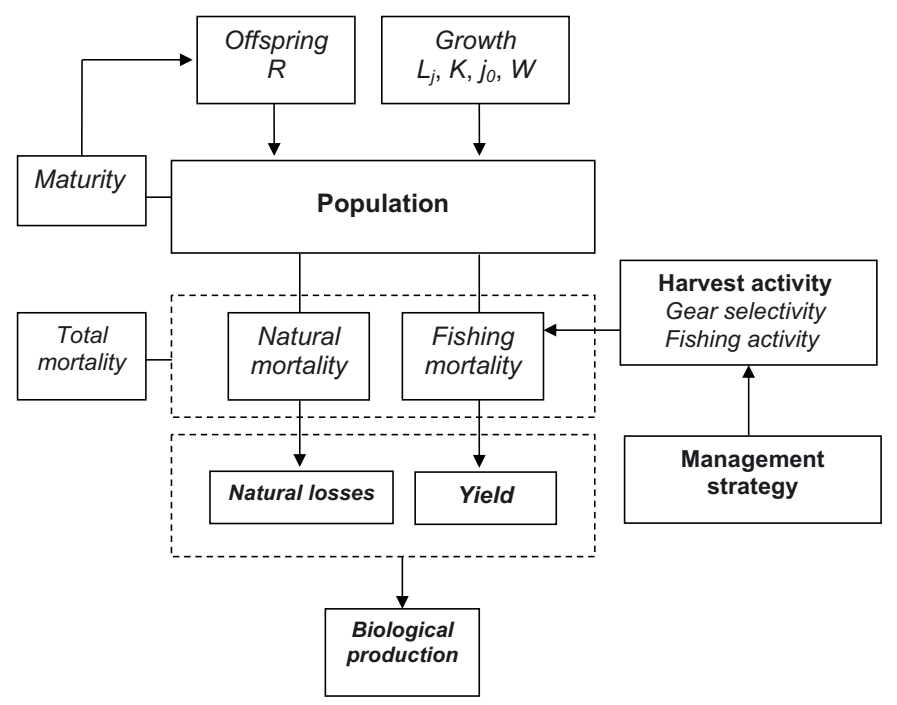

Fig. 1. Schematic view of the functional components of ALADYM model.

- understanding the responsiveness in time of population indicators to different pressure levels, e.g. mean length or age of the spawning population; and

- searching for reference points that match the target criteria of sustainability and viability (De Lara et al. 2007).

\section{The ALADYM model}

\subsection{Model components}

ALADYM (age-length based dynamic model) is an agelength based simulation model developed within the conceptual framework of dynamic pool models following Thompson and Bell (1934). The model (Fig. 1) simulates population dynamics of a single species accounting for sex differences in growth, maturity and mortality using a monthly time step $\Delta t$.

The discrete population dynamics are formulated by following the simultaneous evolution of several cohorts at monthly intervals:

$$
N_{(t+\Delta t), j}=N_{t, j} e^{-\left(F_{t, j}+M_{j}\right) \cdot \Delta t}
$$

where $j$ indicates the age, $t$ the time, $M$ and $F$ the natural and fishing mortality respectively.

Individual growth is modelled using the von Bertalanffy growth function:

$$
L_{j}=L_{\infty} \cdot\left(1-e^{-K \cdot\left(j-j_{0}\right)}\right)
$$

where $L_{j}$ is length at age $j$ and $K, L_{\infty}$ and $j_{0}$ are the VBG parameters (notice a slight change with respect to the common notation $-j_{0}$ instead of $t_{0}-$ for consistency within this manuscript). For each age the average length $\bar{L}_{j}$ in the age interval $(j, j+\Delta j)$ is calculated as:

$$
\bar{L}_{j}=L_{\infty}+\frac{\left(L_{j}-L_{j+\Delta j}\right)}{K \cdot \Delta j}
$$


as in Cadima 2002; details are provided in the Appendix 2.

The weight at average length, for each age, is calculated from the length-weight relationship

$$
W_{j}=\mathrm{a} \bar{L}_{j}^{\mathrm{b}} .
$$

Natural mortality can be constant for each age, or a vector by age calculated outside the model and used as input. A third option is to calculate a vector inside the model based on Chen and Watanabe (1989):

$M_{j}= \begin{cases}\frac{K}{1-e^{-K \cdot\left(j-j_{0}\right)}} & K \leqslant j_{M} \\ \frac{K}{1-d+K \cdot d \cdot\left(j-j_{M}\right)-\frac{1}{2} K^{2} \cdot d \cdot\left(j-j_{M}\right)^{2}} & j>j_{M}\end{cases}$

where $d=e^{-K\left(j_{M}-j_{0}\right)}$ and $j_{M}=-\frac{1}{K} \ln \left|1-e^{K j_{0}}\right|+j_{0}$.

The parameters $j_{0}$ and $K$ are from the von Bertalanffy growth equation; $j_{M}$ represents the "age at the end of the reproductive span" according to Chen and Watanabe (1989). The relationship between age and natural mortality is convex. The Chen and Watanabe natural mortality model works for negative values of $j_{0}$.

The total mortality $Z_{t}$ is an input to the model and is estimated off-line, for example, from trawl-survey data. Its values are used to calculate the parameter $Z_{t}^{\prime}$ through the procedure described in Section 3.

To build up the fishing pattern $F_{t, j}$, the fishing mortality is then modelled for each cohort as a function of length as in Sparre and Venema (1998), but using in addition a fishing activity coefficient $f_{\text {act }}(\mathrm{t})$, which would be 0 in the case of a fishery closure:

$$
F_{t, j}=F_{f}^{\prime}(t) \cdot \operatorname{Sel}\left(\bar{L}_{j}, t\right) \cdot f_{\mathrm{act}}(t)
$$

where $\operatorname{Sel}\left(\bar{L}_{j}, t\right)$ is the selectivity of the fishery on fish of size $\bar{L}_{j}$ at the time step $t, F_{f}^{\prime}(t)$ is related to the fishing mortality by $F_{f}^{\prime}(t)=Z_{t}^{\prime}-M_{\min }$ and $M_{\min }$ is the minimum value of $M$.

Hence, the model calculates the parameters for the Equation (1) split by age and time as:

$$
Z_{t, j}^{\prime \prime}=F_{t, j}+M_{j}
$$

The proportion of retained fish $\operatorname{Sel}\left(\bar{L}_{j}, t\right)$ of the cohort $j$ is calculated at time $t$ from one of the two following relationships (Sparre and Venema 1998) that represent different options for the user:

$$
\begin{gathered}
\operatorname{Sel}\left(\bar{L}_{j}, t\right)=\frac{1}{1+e^{\left(\frac{2 \cdot \ln (3)}{S R_{t}}\right) \cdot\left(L_{50 \%}(t)-\bar{L}_{j}\right)}} \\
\operatorname{Sel}\left(\bar{L}_{j}, t\right)=\frac{1}{1+e^{\left(\frac{2 \cdot \ln (3)}{S R_{t}}\right) \cdot\left(L_{50 \%}(t)-\bar{L}_{j}\right)}} \cdot \frac{1}{1+e^{\left(\frac{-2 \cdot \ln (3)}{D S R_{t}}\right) \cdot\left(D_{50 \%}(t)-\bar{L}_{j}\right)}}
\end{gathered}
$$

where $L_{50 \%}(t)$ is the length at first capture and $S R_{t}=$ $L_{75 \%}(t)-L_{25 \%}(t)$ is the selection range, while $D_{50 \%}(t)$ and $D S R_{t}=D_{25 \%}(t)-D_{75 \%}(t)$ are the parameters describing the descending limb of the model, which accounts for the reduced vulnerability of larger fish.
Yield $(Y)$ during the time interval $(t, t+\Delta t)$ for cohort $j$ is then computed following the Baranov equation as (Sparre and Venema 1998):

$$
Y_{t, j}=\frac{F_{t, j}}{Z_{t, j}^{\prime \prime}} \cdot N_{t, j} \cdot\left(1-e^{-Z_{t, j}^{\prime \prime} \cdot \Delta t}\right) \cdot W_{j}
$$

where $W_{j}$ is the weight at age $j$ from the Equation (3b).

Maturity Mat is a function of length $L$ and is calculated following an ogive model (Quinn and Deriso 1999). The proportion of mature fish at age is then:

$$
M a t_{j}=\frac{1}{1+e^{\left(\frac{2 \cdot \ln (3)}{M R}\right) \cdot\left(L_{m 50 \%}-\bar{L}_{j}\right)}}
$$

where $L_{m 50 \%}$ is the length at which $50 \%$ of fish are mature and $M R=L_{m 75 \%}-L_{m 25 \%}$ is the maturity range, i.e. the difference between the length at which $75 \%$ and $25 \%$ of fish are mature.

For the exploited population $(F>0)$, the total biomass $B_{t, j}$ and the spawning stock biomass $S S B_{t, j}$ of the cohort $j$ at time $t$ are then simply:

$$
\begin{aligned}
B_{t, j} & =N_{t, j} \cdot W_{j} \\
S S B_{t, j} & =N_{t, j} \cdot W_{j} \cdot M t_{j}
\end{aligned}
$$

Similarly, for the unexploited population $(F=0)$ the total biomass $\left(U B_{t, j}\right)$ and the spawning stock biomass $\left(U S S B_{, t, j}\right)$ of the cohort $j$ at time $t$ are calculated as:

$$
\begin{aligned}
U B_{t, j} & =U N_{t, j} \cdot W_{j} \\
U S S B_{t, j} & =U N_{t, j} \cdot W_{j} \cdot M a t_{j}
\end{aligned}
$$

where $U N_{t}$, is the population in numbers of the cohort $j$ at time $t$ when $F=0$

There is a choice of several stock-recruitment relationships whose parameters can be input to ALADYM:

Beverton and Holt (1957): $R=\frac{S}{(\alpha+\beta S)}$

Ricker (1954): $R=\alpha \cdot S \cdot e^{(-\beta S)}$

Shepherd (1982): $R=\alpha \cdot S /\left[1+(S / \gamma)^{\beta}\right]$

Barrowman and Myers (2000):

hockey stick $R=\alpha \cdot \min \left(S, S^{*}\right)=\left\{\begin{array}{l}\alpha \cdot S \text { if } S<S^{*} \\ \alpha \cdot S^{*} \text { if } S \geqslant S^{*}\end{array}\right.$

quadratic hockey stick:

$R= \begin{cases}\alpha \cdot S & \text { if } S \leqslant S^{*} \cdot(1-\delta) \\ \alpha \cdot\left(S-\frac{\left(S-S^{*} \cdot(1-\delta)\right)^{2}}{4 \delta \cdot S^{*}}\right) & \text { if } S^{*} \cdot(1-\delta)<S<S^{*} \cdot(1+\delta) \\ \alpha \cdot S^{*} & \text { if } S \geqslant S^{*} \cdot(1+\delta)\end{cases}$

where $R$ and $S$ represent the number of recruits and spawners respectively, whilst $\alpha, \beta, \gamma, \delta, S^{*}$ are model parameters. The number of spawners at time $t$ is calculated as

$$
S_{t}=\sum_{j} N_{(t-\lambda), j} \cdot M a t_{j}
$$


where $\lambda$ is the time (in months) elapsing from spawning to birth. This parameter can be useful for example for species that incubate eggs for longer times like the Norway lobster or some Elasmobranchs.

The timing of recruitment events, i.e. the months when they occur and their duration, is flexible and depends on species' biology. In fact, to account for recruitment pulses the function $\mathrm{PoO}_{t}$ is introduced:

$$
R_{t}^{\prime}=P o O_{t} \cdot R_{t}\left(S_{t}\right)
$$

where $\mathrm{PoO}_{t}$ is the proportion of offspring entering the stock in the month $t, R_{t}$ is the monthly number of offspring as derived from the stock-recruitment relationship and $R_{t}^{\prime}$ the number of offspring effectively entering the population at month $t$. This number is split by sex using the monthly sex-ratio given in the input, according to the biological knowledge on the species.

Instead of using these stock-recruitment relationships, the model can be fed by a vector of offspring. This method can assist the user for hindcasting simulations.

We introduced a uniformly distributed multiplier for $R_{t}^{\prime}$ to add a source of stochasticity to the stock-recruitment equations in order to model small perturbations in the environment; it is suggested that these perturbations should be kept small so as not to void the effects of the stock-recruitment relationship used. The list of the main model parameters is reported in Table 1.

\subsection{Management measures}

Several management measures are implemented in ALADYM. They concern interventions regarding total mortality $Z_{t}$, gear selectivity (size at first capture $L_{50 \%}$ and selection range) and fishing activity (through $f_{a c t}$ in Eq. (5)). The effects of these measures are then analysed in terms of long-term population sustainability. The ratio between the mean spawning stock biomass and the mean unexploited spawning stock biomass $S S B / U S S B$ is also estimated for each harvesting scenario. To calculate this indicator, two populations are simulated: the exploited affected by total mortality and the unexploited one, on which only natural mortality is acting.

\subsection{Adding stochasticity to population dynamics}

To take into account the uncertainty in the knowledge of parameter values, the ALADYM model has been embedded into a larger framework where some key parameters are represented by their probability density functions $(p d f s)$ instead of by their average values. The $p d f s$ can be assigned to each parameter independently and are chosen from the following list: log-normal, normal, gamma and uniform.

Following the Monte-Carlo paradigm, random samples for recruitment, individual growth and size at maturity are drawn from the selected $p d f s$ (Table 2) to create the initial population distribution. This population is then allowed to evolve using the ALADYM model. The outputs from the runs are used to calculate descriptive statistical parameters (mean, standard deviation, distribution) useful to measure the variability of the results.
Table 1. List of parameters of the equations used in ALADYM whose values need to be provided.

\begin{tabular}{lll}
\hline Parameter & Description & Equation \\
\hline$K, L_{\infty}, j_{0}$ & von Bertalanffy growth & 2 \\
& function parameters & \\
a, b & Length-weight relationship & $3 \mathrm{~b}$ \\
$L_{50 \%}(t), S R_{t}, D_{50 \%}(t)$, & Selection parameters & $7 \mathrm{a}, 7 \mathrm{~b}$ \\
$D S R_{t}$ & & \\
$L_{m 50 \%}, M R$ & Maturity ogive parameters & 9 \\
& & \\
& Beverton and Holt, Ricker, \\
$\alpha, \beta, \gamma, \delta, S^{*}$ & $\begin{array}{l}\text { Shepherd and hockey-stick } \\
\text { stock recruitment }\end{array}$ & $14 \mathrm{a}, 14 \mathrm{~b}$, \\
& $\begin{array}{l}\text { relationships } \\
\end{array}$ & \\
\hline
\end{tabular}

Table 2. Input parameters to which a probability density function $(p d f)$ can be associated for Monte Carlo simulations

\begin{tabular}{lll}
\hline Parameter & Description & $p d f$ \\
\hline$K, L_{\infty}$, & von Bertalanffy growth & \\
& function parameters & log-normal, \\
$R$ & Offsprings & normal, gamma, \\
$L_{m 50 \%, M R}$ & Maturity ogive parameters & uniform \\
\hline
\end{tabular}

\subsection{Simulation steps}

A flow diagram for using ALADYM is shown in Figure 2. The first step is to read the model parameter values and to initialize the population state vector (numbers at age and biological features in month 0 ) under equilibrium condition. Then a set of $n$ (typically 100) simulations is run using randomly sampling for number of recruits, growth parameters and sizes at maturity values from user specified distributions (see Sect. 2.3). Using the model described in Section 2, the population goes through a burn-in period corresponding typically to several life-spans of the sex with the longest longevity (step 2) so as to allow introduction of the time-variant effects (seasonality of offspring and the stock-recruitment relationship), thus eliminating the transient behaviour attributable to the initial equilibrium condition. Four populations are simulated: an exploited and an unexploited one $(F=0)$ for each sex.

After the initialisation period, the population is projected forward for $m$ years applying the selected management measures (step 3). Recruits are deterministically simulated using one of the stock-recruitment functions (Eq. 14).

\section{ALADYM in practice}

The ALADYM model does not have any hard-coded default parameter values so the user has to provide values for all parameters or their distributions (see list of parameters of the equations used in ALADYM (Tables 1 and 2). It is crucial to check the coherence of the model parameters supplied, for example by assessing whether simulations exhibit sensible behaviours. Automatic checks include ensuring that $F_{\max }>0$, that fish length at $t_{0}>0$, and that the sex proportion is between 0 and 1 .

One of the parameters highly influencing the behaviour of the model is the vector $Z_{t}$ that is the input total mortality as 

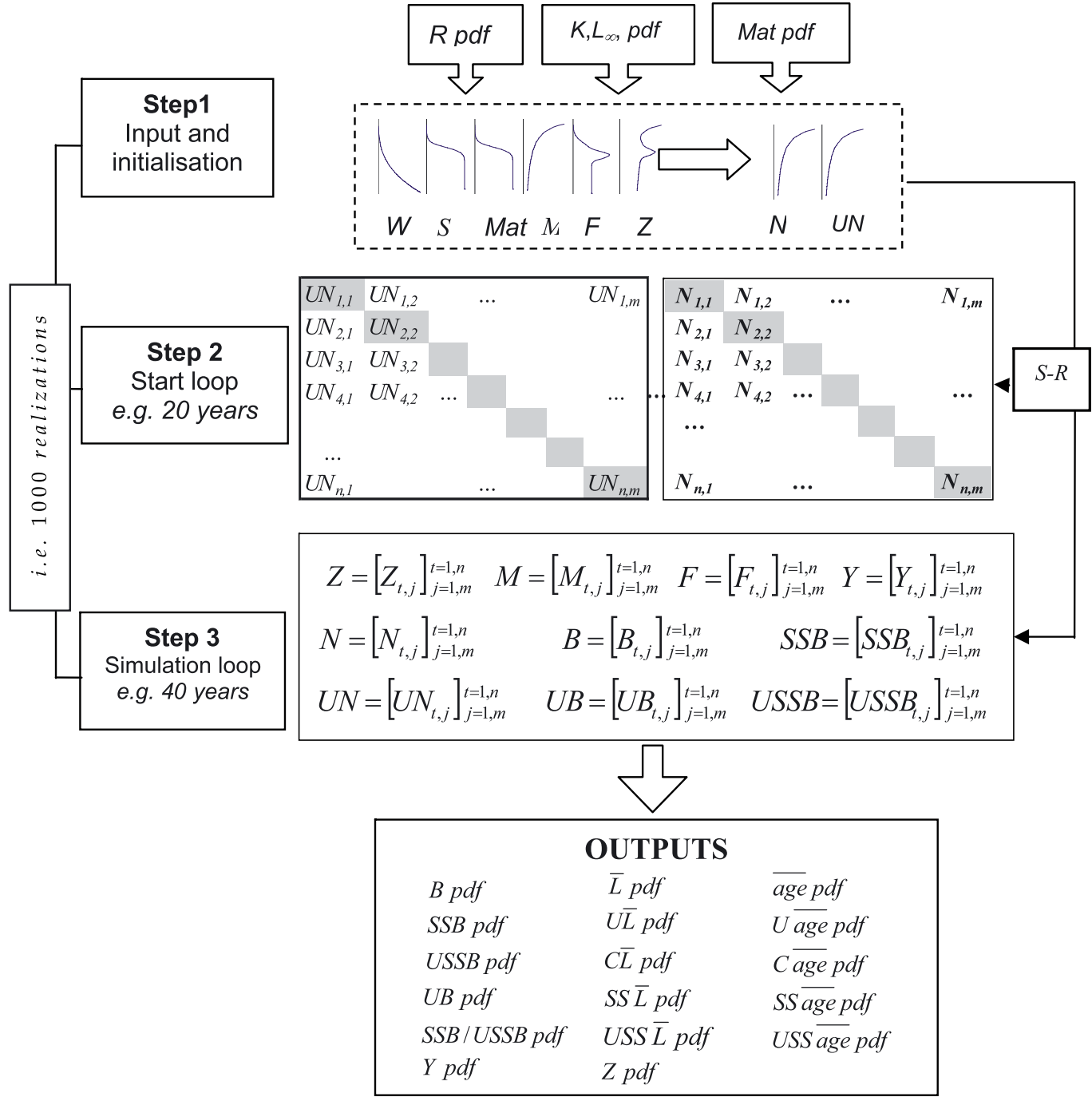

Fig. 2. Schematic view of the ALADYM process and steps. $P d f=$ probability density function; $K, L_{\infty}$ growth parameters, $R=$ recruitment; $W=$ individual weight; $S=$ selectivity; $M a t=$ maturity; $M=$ natural mortality; $F=$ fishing mortality, $Z=$ total mortality; $N=$ exploited population, $U N=$ unexploited population, $B=$ exploited biomass, $S S B=$ exploited spawning stock biomass, $U B=$ unexploited biomass, $U S S B=$ unexploited spawning stock biomass, $S-R=$ stock-recruitment relationship; $\bar{L}=$ average length; $\overline{\text { age }}=$ average age; $S S=$ exploited spawner population; $U S S=$ unexploited spawner population; $C=$ capture in numbers; $Y=$ yield, $t=$ time, $j=$ cohort.

obtained, for example, from scientific surveys. However, this parameter is rarely available split by age at a monthly time step. Thus, as mentioned in Section 2.1, the vector $Z_{t}^{\prime}$ has been introduced to mimic the effect of monthly variations of total mortality. To calculate this vector a specific procedure has been developed. The algorithm initializes the vector $Z_{t}^{\prime}$ with the values available for $Z_{t}$ and it iteratively runs the model adjusting the entries of $Z_{t}^{\prime}$ at each step in order to minimize the differences between the input $Z_{t}$ and the one calculated by the model on a yearly basis as follows (Sinclair 2001):

$$
Z_{t}^{\prime \prime \prime}=\frac{1}{\Delta t} \ln \left(\frac{\sum_{j=1}^{m} N_{t, j}}{\sum_{j=2}^{m} N_{t+\Delta t, j}}\right) ;
$$

where $m$ is the number of cohorts. This optimization is performed according to the Least Square paradigm, therefore at the end of each run the least square difference between the total mortality calculated and the one observed is computed:

$$
\min _{Z^{\prime}} \sum_{t}\left(Z_{t}^{\prime \prime \prime}-Z_{t}\right)^{2}
$$

Convergence is reached when the change in the above objective function is less than $10^{-3}$ between two consecutive iterations. This $Z_{t}^{\prime}$ vector is then used as parameter of the model.

Extensive simulations have shown that model behaviour is influenced by the consistency between the set of life-history parameters and population dynamics (Lembo and Spedicato 2006; Lembo et al. 2007). The model results are thus expected to be particularly sensitive to the choice of stock-recruitment relationship and natural mortality values.

To determine the suitable number of Monte Carlo runs necessary to explore the stochastic population dynamics (Sect. 2.3), we performed some tests using the above described 
least square approach to reconstruct a known distribution (e.g. a gamma distribution). Results showed that a number of runs ranging from 1000 to 10000 approximated the parameters of the known distribution with an error between 1-7\% calculated according the following formula:

$$
e r r=\max \left(\frac{k_{\text {true }}-k_{\text {calc. }}}{k_{\text {true }}} ; \frac{\theta_{\text {true }}-\theta_{\text {calc }} .}{\theta_{\text {true }}}\right)
$$

where $k$ and $\theta$ are the parameters of the gamma distribution. This percentage is better than the precision by which most of the input parameters are known.

Details regarding ALADYM software, inputs and outputs are reported in the Appendix 1.

\section{Conclusion}

ALADYM is based on simulating a biological population and testing different harvesting strategies to investigate the domain of fishery sustainability. In the core model the classical equations of population dynamics are used to build a tool that enables the use of fishery-independent information (e.g. from trawl surveys) as a primary source for prediction.

A considerable variety of models based on fisheries independent data (Needle 2003; Beare et al. 2005; Trenkel 2008; Mesnil et al. 2009) or on meta-analysis and pertinent auxiliary information (Porch et al. 2006) have been developed in recent decades to face problems related to reliability and availability of catch - or landings - data from fisheries. This is to allow the implementation of the precautionary approach (FAO 1996) and adaptive management based on scientific advice also in situations where catch-data are poor (e.g. Pilling et al. 2008), and to assist in the evaluation of management strategies other than TACs, even when landing data are available.

In fisheries stock assessment methodology, a framework based on extensive simulations has become a key approach for evaluating management strategies that can meet multiple objectives, where the operating model $(\mathrm{OM})$ and management procedures (MP) represent the core components of the evaluation system (e.g. Butterworth and Punt 1999; Kell et al. 1999; Punt 2003; Butterworth 2007; Kell et al. 2007; Skagen and Dankel 2007; Haltuch et al. 2008). The framework of the operating models is designed to reflect realism and improve robustness in the advice against uncertainties. Tools and platforms relying upon this or similar conceptual schemes, which usually encompass statistical catch-at-age models (SCA), have been rapidly developed (e.g. for assessment methods: stock synthesis, Methot 2000; CASAL (C++ algorithmic stock assessment laboratory), Bull et al. 2005; and for simulation platforms: FLR (fisheries library in R), Kell et al. 2007), also with a specific focus on bioeconomics (e.g. TEMAS, Ulrich 2007). However, the development and review of a MP for a fishery may require much time (up to several months; Butterworth 2007), given the multidimensional characteristics of the framework. The advantage is that this would make the advisory process more transparent (De Oliveira et al. 2008).

According to Pastoors et al. (2007), hindcasting can be a useful tool for studying the dynamics of a model if the dynamics can be verified by observations. Nonetheless, a limitation can be represented by the available observations that can themselves provide a faulty interpretation of the reality they try to represent.

The exploration of the effects of management strategies through simulations should be regarded as a means for comparing alternative options aimed at advising management decisions for a particular fishery system, a process closely related to the scenario modelling developed by ICES (1995) and referred to as FLR (Kell et al. 1999). However, FLR differs from ALADYM. FLR is an object-orientated programming platform where different tools and objects classes can be placed and interconnected for a Management Strategy Evaluation. ALADYM on the other hand is a pre-defined model that evaluates the effects of different fishing impacts on fish population indicators through a simulation approach. Under the paradigm of the scenario modelling, ALADYM adds to the existing methods an easy and flexible tool that uses simulation processes to explore the consequences, on a single population, of different fishing pressure scenarios, in terms of the effects on several metrics and indicators. The evolution of population dynamics at a small time scale allows analysis and modelling of monthly and seasonal fluctuations of harvest controls; this is particularly useful when species are fairly fast growing and exploitation occurs at an early stage. In the model, harvesting can be modulated by month as well as recruitment, accounting for specific offspring pulses during the year. All this gives the possibility of considering exploitation and biological processes in time, thus providing insight into the temporally related effects of specific management strategies. In addition, ALADYM incorporates a variety of models for the stock recruitment relationship and natural mortality that allow the model to adapt to different stock characteristics.

In the Mediterranean, despite the paucity of time series of catch data, pieces of information regarding the relationships among population stages exist for certain species (Alegrìa-Hernandez and Jukic 1988; Levi et al. 2003), as well as the knowledge derived from modelling of natural mortality (Caddy 1991; Abella et al. 1997) and the biological parameters of the main stocks (Anonymous 2002).

In ALADYM, the analytical modelling provides estimates of the potential results of management measures based on technical aspects, such as gear mesh size and seasonal fishing bans, that are important especially for Mediterranean fisheries. Recent applications assisted the evaluation of the reduction of fishing pressure in the medium and long term in the Italian seas (Anonymous 2007).

The stochastic effects incorporated into some of the key life-history traits simulate the uncertainty in input data and parameter relationships. This allows assessment of the robustness of the results and advice against uncertainties.

ALADYM shortcomings are mainly related to the current lack of spatial and environmental components. In addition, the present version of the model is not efficient for mimicking stock dynamics when a complex exploitation pattern occurs due to the combined action of different fishing strategies with different gears, in different areas, and/or over different time periods. However, routines that overcome these limitations as well as the introduction of non-deterministic association between age and length, are in progress. 
As for other analytical models, ALADYM requires several parameters, albeit this is the consequences of the detailed level of outputs.

Nowadays holistic approaches accounting for stock dynamics, ecological, social and economic implications are recognised to be more robust and, as integrated techniques, better for a multidisciplinary evaluation of fisheries sustainability. Fisheries management must ensure, however, that the effects of fishing are sustainable at the scale of the whole ecosystem as well as for individual stocks (FAO 2003). According to Quinn II and Collie (2005) moving into the era of post-modern sustainability includes, among other things: avoidance of incorrect characterisations resulting from a single-species approach, building on what is already known, and progressing in the single species approaches that can be fruitfully combined with new ecosystem and economic based approaches. Thus, diagnostics of the main targeted stocks are still relevant as part of a more comprehensive evaluation framework. In this way the single-species modelling approach becomes embedded into the more complex Ecosystem Approach to Fishery Management (EAFM; FAO 2003), providing a set of model-based metrics and indicators that can be used in a comprehensive framework to formulate assessment and assist management plans.

Acknowledgements. This study was partially funded by the European Commission under Fisboat project (FP5 - 502572) and also partly supported in a later phase by the Image project (FP6 - 044227). We gratefully acknowledge Verena Trenkel for helpful comments and suggestions. We also thank John Cotter providing supportive remarks to the manuscript.

\section{Appendix 1}

\section{ALADYM Software}

ALADYM is written in the $\mathrm{R}$ language (http://www. r-project.org/) and licensed as open source under GPL2. The data and input parameters can easily be entered using an excel data sheet. The results of the simulation are stored into three Export files (.din for inputs, .dou for outputs, .RData for the R workspace) and saved in the same directory where $\mathrm{R}$ is started using the basename of the input sheet. The software can be downloaded from the Fisboat web-site (http://www.ifremer.fr/ drvecohal/fisboat/), where also a detailed description of the input sheet is available.

ALADYM requires about 25 seconds (assuming 40 years of run-in period and 20 years of simulation) with a Intel (R) Pentium (R) personal computer with a processor of $1.70 \mathrm{GHz}$ and 1 GB RAM.

\section{Input parameters to ALADYM (see also Table 1) are:}

1. von Bertalanffy growth parameters by sex with associated variability,

2. length-weight relationship parameters by sex;

3. maturity ogive parameters by sex $\left(L_{m 50 \%}\right.$ and maturity range; $M R$, see Eq. (9));

4. natural mortality by sex (a constant value or a vector, if not automatically calculated by the model);
5. seed values (minimum, maximum, $\ln$-mean and $l n$ standard deviation) of recruitment by sex;

6. proportion of offsprings entering in the stock by month;

7. stock-recruitment relationship parameters or a vector of recruit numbers by month both with associated variability;

8. time elapsing from spawning to birth;

9. sex-ratio (female/total) of offsprings;

10. $F_{f}^{\prime}(t)$ by month (option 2 ) or from the model (option 1 );

11. $Z_{t}$ by sex;

12. selection ogive parameters ( 2 options) of the gear used by the fleet at time $(t)$ : selection length $L_{50 \%}$, selection range $S R$, deselection length $D_{50 \%}$ and deselection range $D S R$ (see Eq. (7b));

13. fishing activity coefficient by month $(0$, in case of absence of fishing activity).

The automatically produced outputs are

Export data file (.dou):

1. exploited and unexploited population by sex, per month and age;

2. exploited and unexploited biomass by sex, per month and age;

3. exploited and unexploited population of females belonging to the spawning stock per month;

4. total mortality $Z_{t}^{\prime \prime \prime}$ calculated by the model for females, males and the whole population in each month and year of the simulation (see Eq. (17));

5. exploited and unexploited biomass per month;

6. exploited and unexploited spawning stock biomass per month;

7. ratio between exploited and the unexploited spawning stock biomass per month;

8. average length and age of exploited and unexploited populations per month;

9. average length and age of exploited and unexploited spawning populations per month;

10. yield in tons per month;

11. average length and age of catches per month;

12. fishing mortality per month calculated as;

$$
F_{t}=\frac{1}{\Delta t} \ln \left(\frac{\sum_{j=1}^{\infty} N_{t, j}}{\sum_{j=2}^{\infty} N_{t+\Delta t, j}^{F}}\right),
$$

where $N_{t+\Delta t, j}^{F}$ is the number of survivors at the time $t+\Delta t$ under the hypothesis that only fishing mortality is acting;

13. biomass of natural losses and total biological production per month.

Plots per year of the outputs listed from items 4 to 13 are also produced.

Plots of the $p d f s$ and the cumulative ( $c p d f s$ ) are interactively produced per year for the same items listed above.

\section{Additional outputs:}

1. average length at age and age by sex;

2. natural mortality at age/length by sex;

3. weight at age/length by sex;

4. proportion of mature individuals at age/length by sex. 
These outputs help the user to check the results obtained from the sub-models, in particular those related to the van Bertalanffy growth function (VBGF), the length-weight relationship, the natural mortality, and the maturity.

\section{Appendix 2}

Justification of the Equation (3a):

$$
\begin{aligned}
& \bar{L}=\frac{1}{\Delta j} \int_{j}^{j+\Delta j} L_{\infty}\left(1-e^{-k\left(\tau-j_{0}\right)}\right) d \tau \\
& \bar{L}=\frac{L_{\infty}}{\Delta j}\left[\int_{j}^{j+\Delta j} d \tau-\int_{j}^{j+\Delta j} e^{-k\left(\tau-j_{0}\right)} d \tau\right] \\
& \bar{L}=\frac{L_{\infty}}{\Delta j}\left[[\tau]_{j}^{j+\Delta j}-\left[-\frac{1}{k} \cdot e^{-k\left(\tau-j_{0}\right)}\right]_{j}^{j+\Delta j}\right] \\
& \bar{L}=\frac{L_{\infty}}{\Delta j}\left[(j+\Delta j-j)+\frac{1}{k}\left[\left(e^{-k\left(j+\Delta j-j_{0}\right)}\right)-\left(e^{-k\left(j-j_{0}\right)}\right)\right]\right] \\
& \bar{L}=\frac{L_{\infty}}{\Delta j}\left[(j+\Delta j-j)+\frac{1}{k}\left[\left(e^{-k\left(j+\Delta j-j_{0}\right)}\right)-\left(e^{-k\left(j-j_{0}\right)}\right)+1-1\right]\right] \\
& \bar{L}=\frac{L_{\infty}}{\Delta j}\left[\Delta j+\frac{1}{k}\left[\left(1-e^{-k\left(j-j_{0}\right)}\right)-\left(1-e^{-k\left(j+\Delta j-j_{0}\right)}\right)\right]\right] \\
& \bar{L}=L_{\infty}+\frac{1}{k \cdot \Delta j}\left[L_{\infty}\left(1-e^{-k\left(j-j_{0}\right)}\right)-L_{\infty}\left(1-e^{-k\left(j+\Delta j-j_{0}\right)}\right)\right] \\
& \bar{L}=L_{\infty}+\frac{L_{j}-L_{j+\Delta j}}{k \cdot \Delta j} .
\end{aligned}
$$

\section{References}

Abella A., Caddy J.F., Serena F., 1997, Do natural mortality and availability decline with age? An alternative yield paradigm for juvenile fisheries, illustrated by hake fishery in the Mediterranean. Aquat. Living Resour. 10, 257-269.

Abella A., Belluscio A., Bertrand J., Carbonara P., Giordano D., Sbrana M., Zamboni A., 1999, Use of MEDITS data and commercial fleet information for the assessment of some Mediterranean demersal resources. Aquat. Living Resour. 12, 155-166.

Alegrìa-Hernandez V., Jukic S., 1988, Stock-recruitment relationship for the hake (Merluccius merluccius L.) from the open middle Adriatic-Jabuka Pit. FAO Fish. Rep. 394, 137-141.

Anonymous, 2002, Stock assessment in the Mediterranean. Final Report EU Project No. 99/047.

Anonymous, 2007, Programma Operativo FEP per il settore pesca, Italia, CCI: 2007IT14FPO001, 178 pp. http://www. fondieuropei2007-2013.it/upload\%5CFEP\%5C20071115_PA_ programma_operativo_FEP.pdf

Bull B., Francis R.I.C.C., Dunn A., McKenzie A., Gilbert D.J., Smith M.H., 2005, CASAL (C++ algorithmic stock assessment laboratory): CASAL User Manual v2.07- 2005/08/21. NIWA Tech. Rep. 127.

Butterworth D.S., 2007, Why a management procedure approach? Some positives and negatives. ICES J. Mar. Sci. 64, 613-617.

Butterworth D.S., A.E. Punt, 1999, Experiences in the evaluation and implementation of management procedures. ICES J. Mar. Sci. 56, 985-998.
Beare D.J., Needle C.L., Burns F. Reid D.G., 2005, Using survey data independently from commercial data in stock assessment: an example using haddock in ICES Division VIa. ICES J. Mar. Sci. 62, 996-1005.

Beverton R.J.H., Holt S.J., 1957, On the dynamics of exploited fish populations. UK Min. Agric. Fish., Fish. Invest. (Ser. 2) No. 19.

Barrowman N.J., Myers R.A., 2000, Still more spawner-recruitment curves: the hockey stick and its generalizations. Can. J. Fish. Aquat. Sci. 57, 665-676.

Caddy J.F., 1991, Death rates and time intervals: is there an alternative to the constant natural mortality rate axiom? Rev. Fish Biol. Fish. $1,109-138$.

Caddy J.F., 2006, The potential use of indicators, reference points and the traffic light convention for managing Black Sea fisheries. In: Lembo G. (Ed.) Selected papers presented at the Workshop on biological reference points. Rome, 20-21 April 2004. General Fisheries Commission for the Mediterranean. Studies and Reviews No. 83. Rome, FAO.

Chen S., Watanabe S., 1989, Age dependence of natural mortality coefficient in fish population dynamics. Nippon Suisan Gakkaishi 55, 205-208.

Cotter J., Petitgas P., Abella A., Apostolaki P., Mesnil B., Politou C.Y, Rivoirard J., Rochet M.J., Spedicato M,. Trenkel V.M, Woillez M., 2009, Towards an ecosystem approach to fisheries management (EAFM) when trawl surveys provide the main source of information. Aquat. Living Resour. 22, 243-254.

Darby C.D., Flatman S. 1994, Lowestoft VPA Suite Version 3.1 User Guide. MAFF: Lowestoft.

De Lara M., Doyen L., Guilbaud T., Rochet M.J., 2007, Is a management framework based on spawning-stock biomass indicators sustainable? A viability approach. ICES J. Mar. Sci. 64, 1-7.

De Oliveira J.A.A, Kell L.T., Punt A.E., Roel B.A., Butterworth D.S., 2008, Managing without best predictions: the management strategy evaluation framework. In: Payne A., Cotter J., Potter T. (Eds.) Advances in Fisheries Science. 50 years on from Beverton and Holt. Blackwell Publishing, Oxford, pp. 104-134.

FAO, 1996, Technical Guidelines for Responsible Fisheries. No. 2. Rome, FAO: $54 \mathrm{p}$.

FAO, 2003, The ecosystem approach to fisheries. FAO Technical Guidelines for Responsible Fisheries. No. 4, Suppl. 2. Rome.

Gallucci V.F., Saila S.B., Gustafson J., Rothschild B.J. (Eds.). 1996, Stock assessment: quantitative methods and applications for small-scale fisheries. CRC Press, Lewis Publishers.

Gulland J.A., 1969, Manuel des méthodes d'évaluation des stocks d'animaux aquatiques. Première partie-Analyse des populations. Manuels FAO de science halieutique, $\mathrm{N}^{\circ} 4$.

Haddon M., 2001, Modelling and quantitative methods in fisheries. Chapman \& Hall CRC Press.

Haltuch M.A., Punt, A.E., Dorn M.W., 2008, Evaluating alternative estimators of fishery management reference points. Fish. Res. 94, 210-303.

Hilborn R., Walters C.J., 1992, Quantitative Fisheries Stock Assessment. Choice, Dynamics \& Uncertainty. Chapman \& Hall.

Hoggarth D.D., Abeyasekera S., Arthur R.I., Beddington J.R., Burn, R.W., Halls A.S., Kirkwood G.P., McAllister M., Medley P., Mees C.C., Parkes G.B., Pilling G.M., Wakeford R.C., Welcomme R.L., 2006, Stock assessment for fishery management - A framework guide to the stock assessment tools of the fisheries management science programme (FMSP). FAO Fish. Tech. Pap. No. 487, Rome, FAO.

Kell L.T., O’Brien C.M., Smith M.T., Stokes T.K., Rackham B.D., 1999, An evaluation of management procedures for implementing a precautionary approach in the ICES context for North Sea plaice (Pleuronectes platessa L.). ICES J. Mar. Sci. 56, 834-845. 
Kell L.T., Mosqueira I., Grosjean P., Fromentin J.M., Garcia D., Hillary R., Jardim E., Mardle S., Pastoors M.A., Poos J.J., Scott F., Scott R.D., 2007, FLR: an open-source framework for the evaluation and development of management strategies. ICES J. Mar. Sci. 64, 640-646.

ICES, 1995, Report of the Working Group on Long-term Management Measures. ICES CM 1995/Assess.15.

Levi D., Andreoli M.G., Bonanno A., Fiorentino F., Garofalo G., Mazzola S., Norrito G., Patti B., Pernice G., Ragonese S., Giusto G.B., Rizzo P., 2003, Embedding sea surface temperature anomalies into the stock recruitment relationship of red mullet (Mullus barbatus L. 1758) in the Strait of Sicily. Scient. Mar. 67, 259268.

Lembo G., Spedicato M.T,. 2006, Red mullet assessment in the GSA 10 using ALADYM simulation model. Sub-Committee Stock Assessment SAC-GFCM, FAO Headquarters, 11-14 Sept. 2006.

Lembo G., Martino S., Abella A.J., Fiorentino F., Spedicato M.T., 2007, ALADYM (Age-Length Based Dynamic Model): a stochastic simulation tool to predict population dynamics and management scenarios using fishery-independent information. Workshop on trawl survey based monitoring fishery system in the Mediterranean, GFCM, FAO, 26-28 March 2007.

Lleonart J., Salat J., 1997, VIT: Software for fishery analysis,. User's manual. FAO Computerised Information, Ser. Fish. 11.

McGarvey R., Feenstra J., Ye Q., 2007, Modeling fish number dynamically by age and length: partitioning cohort into "slices". Can. J. Fish. Aquatic. Sci. 64, 1157-1173.

Mesnil B., 2003, The catch-survey analysis (CSA) method of fish stock assessment: an evaluation using simulated data. Fish. Res. 63, 193-212

Mesnil B., Cotter J., Fryer R.J., Coby L. Needle C.L., Trenkel V.M., 2009, A review of fishery-independent assessment models, and initial evaluation based on simulated data. Aquat. Living Resour. 22, 207-216.

Methot R.D., 2000, Technical description of the stock synthesis assessment program. NOAA Technical Memorandum NMFS \{NWFSC $\{43$. http://www.nwfsc.noaa.gov/publications/ techmemos/tm43/tm43.pdf

Needle C.L. 2003, Survey-based assessments with surba. Working Document to the ICES Working Group on Methods of Fish Stock Assessment, Copenhagen, 29 Jan.-5 Febr. 2003.

Quinn T.J.II,. Deriso R.B., 1999, Quantitative fish dynamics. Oxford University Press, Oxford.

Pastoors M.A., Poos J.J., Kraak S.B.M., Machiels M.A.M., 2007, Validating management simulation models and implications for communicating results to stakeholders. ICES J. Mar. Sci. 64, 818-824.
Pilling G.M., Apostolaki P., Failler P., Floros C., Large P.A., Morales-Nin B., Reglero P., Stergiou K.I., Tsikliras A.C., 2008, Assessment and management of data-poor fisheries. In: Payne A., Cotter J., Potter T. (Eds.) Advances in Fisheries Science. 50 years on from Beverton and Holt. Blackwell Publishing, Oxford, pp. 280-305.

Pope J.G., 1972, An investigation on the accuracy of virtual population analysis using cohort analysis. Int. Comm. Northw. Atl. Fish. Res. Bull. 9, 65-74.

Porch C.E., Eklund A.M., Scott G.P., 2006, A catch-free stock assessment model with application to goliath grouper (Epinephelus itajara) off southern Florida. Fish. Bull. 104, 89-101.

Prager M., 2005, Users Manual for ASPIC: A Stock-Production Model Incorporating Covariates (vers.5), NMFS, Beaufort Lab. Doc. BL-2004-01.

Punt A.E., Hilborn R., 1996, Biomass dynamic models. User's manual. FAO Computerized Information Series (Fisheries) No. 10. Rome, FAO.

Punt A.E., 2003, Evaluating the efficacy of managing West Coast groundfish resources through simulations. Fish. Bull. 101, 860873.

Ricker W.E., 1954, Stock and recruitment. J. Fish. Res. Board Can. 11, 559-623.

Shepherd J.G., 1982, A versatile new stock-recruitment relationship for fisheries, and the construction of sustainable yield curves. J. Cons. Explor. Mer 40, 67-75.

Sinclair A.F., 2001, Natural mortality of cod (Gadus morhua) in the Southern Gulf of St Lawrence. ICES J. Mar. Sci. 58, 1-10.

Sparre P., Venema S.C., 1998, Introduction to tropical fish stock assessment. Part 1, manual. FAO Fish. Techn. Pap. 306 Rev. 2.

Skagen D.W., Dankel D. 2007, Management with sparse data. ICES CM 2007/O:22.

Thompson W.F., Bell F.H., 1934, Biological statistics of the Pacific halibut fishery. 2. Effect of changes in intensity upon total yield and yield per unit of gear. Rep. Int. Fish. (Pacific Halibut) Comm. $\mathrm{N}^{\circ} 8$.

Trenkel V.M., 2008, A two-stage biomass random effects model for stock assessment without catches: What can be estimated using only survey biomass indices? Can. J. Fish. Aquat. Sci. 65, 10241035.

Trenkel V.M., Rochet M.J., Mesnil B., 2007, From model-based prescriptive advice to indicator-based interactive advice. ICES J. Mar. Sci. 64, 768-774.

Ulrich C., Andersen B.S., Sparre P.J., Nielsen J.R., 2007, TEMAS: fleet-based bio-economic simulation software to evaluate management strategies accounting for fleet behaviour. ICES J. Mar. Sci. 64, 647-651. 